\title{
An experimental animal model of aseptic loosening of hip prostheses in sheep to study early biochemical changes at the interface membrane
}

\author{
Alexander O El-Warrak ${ }^{1,3}$, Marvin Olmstead ${ }^{2}$, Rebecca Schneider ${ }^{1}$, \\ Lorenz Meinel $^{1}$, Regula Bettschart-Wolfisberger ${ }^{1}$, Margarete K Akens ${ }^{1}$, \\ Joerg Auer ${ }^{1}$ and Brigitte von Rechenberg*1
}

\author{
Address: ${ }^{1}$ Musculoskeletal Research Unit, Dept. of Veterinary Surgery, University of Zurich, Winterthurerstr. 260 , 8057 Zurich, Switzerland, \\ ${ }^{2}$ Department of Veterinary Clinical Sciences, The Ohio State University, College of Veterinary Medicine, Columbus, OH 43210, USA and ${ }^{3} \mathrm{CNPq}$, \\ Brasilia, Brazil \\ Email: Alexander O El-Warrak - warrakel@uiuc.edu; Marvin Olmstead -thrdvm@worldnet.att.net; Rebecca Schneider - rebecca.s@bluewin.ch; \\ Lorenz Meinel - lorenz.meinel@pharma.ethz.ch; Regula Bettschart-Wolfisberger - rbettschart@vetclinics.unizh.ch; \\ Margarete Akens - makens@ovc.uoguelph.ca; Joerg Auer - jauer@vetclinics.unizh.ch; Brigitte von \\ Rechenberg* - bvonrechenberg@vetclinics.unizh.ch \\ * Corresponding author
}

Published: 03 March 2004

BMC Musculoskeletal Disorders 2004, 5:7
Received: 15 October 2003

Accepted: 03 March 2004

This article is available from: http://www.biomedcentral.com/I47I-2474/5/7

(c) 2004 El-Warrak et al; licensee BioMed Central Ltd. This is an Open Access article: verbatim copying and redistribution of this article are permitted in all media for any purpose, provided this notice is preserved along with the article's original URL.

\begin{abstract}
Background: Aseptic loosening of hip prosthesis as it occurs in clinical cases in human patients was attributed to wear particles of the implants, the response of the tissue dominated by macrophages and the production of inflammatory mediators and matrix degrading enzymes; however, the cascade of events initiating the process and their interaction regarding the time course is still open and discussed controversially. Therefore, the goal of this study was to establish an experimental animal model in sheep allowing to follow the cascade of early mechanical and biochemical events within the interface membrane and study the sequence of how they contribute to the pathological bone resorption necessary for aseptic loosening of the implant.
\end{abstract}

Methods: A cemented modular system (Biomedtrix) was used as a hip replacement in 24 adult Swiss Alpine sheep, with one group receiving a complete cement mantle as controls $(n=12)$, and the other group a cement mantle with a standardized, lateral, primary defect in the cement mantle $(n=12)$. Animals were followed over time for 2 and 8.5 months ( $n=6$ each). After sacrifice, samples from the interface membranes were harvested from five different regions of the femur and joint capsule. Explant cell cultures were performed and supernatant of cultures were tested and assayed for nitric oxide, prostaglandin E2, caseinolytic and collagenolytic activity. RNA extraction and quantification were performed for inducible nitric oxide synthase, cyclooxygenase-2, interleukin $\mathrm{I}$, and interleukin 6. Overall differences between groups and time periods and interactions thereof were calculated using a factorial analysis of variance (ANOVA).

Results: The development of an interface membrane was noticed in both groups at both time points. However, in the controls the interface membrane regressed in thickness and biological activity, while both variables increased in the experimental group with the primary cement mantle defect over time. Nitric oxide (NO) and PGE2 concentrations were higher in the 8.5 months group $(P<0.000 I)$ compared to the 2 months group with a tendency for the unstable group to have higher concentrations. The same was true for collagenolytic activity $(P$ $=0.05)$, but not for caseinolytic activity that decreased over time $(P<0.000 \mathrm{I})$. 
Conclusion: In this study, a primary cement mantle defect of the femoral shaft elicited biomechanical instability and biochemical changes over time in an experimental animal study in sheep, that resembled the changes described at the bone cement-interface in aseptic loosening of total hip prosthesis in humans. The early biochemical changes may well explain the pathologic bone resorption and formation of an interface membrane as is observed in clinical cases. This animal model may aid in future studies aiming at prevention of aseptic loosening of hip prosthesis and reflect some aspects of the pathogenesis involved.

\section{Background}

Aseptic loosening is reported as a major cause of failure in total hip replacement. It is the result of a chronic inflammatory process characterized by the formation of fibrous tissue or a synovial-like membrane between the bone and the bone cement in cemented hip prosthesis and between the metal implant and bone in cementless hip prosthesis [1]. The so-called interface membrane is involved in the pathologic bone resorption responsible for the loosening of the prosthesis components $[1,2]$ and typically consists of a combination of fibrous tissue and macrophages [3].

The host specific local inflammatory response within the bone has been shown to be elicited by both, micromotion and wear particles [4]. The inflammatory response is characterized by the activation of cellular mechanisms and the increased production of cytokines like interleukin $1 \beta$ (IL$1 \beta$ ), interleukin 6 (IL-6), tumor necrosis factor a (TNF- $\alpha$ ), local inflammatory mediators as prostaglandin $\mathrm{E}_{2}\left(\mathrm{PGE}_{2}\right)$ and nitric oxide (NO), as well as neutral matrix metalloproteinases, such as collagenase (MMP1 and 13), and stromelysin (MMP3) [5-15].

Cultured macrophages exposed to wear particles are capable of activating osteoblasts in vitro [16] that in turn seem to be responsible for the recruitment and activation of osteoclasts involved in phagocytosis and pathological bone resorption $[5,17]$. The signal transduction among these cells is mediated by the local factors mentioned above, and was also shown to be connected to high macrophage-colony stimulating factor found in periprosthetic tissue in humans [15]. High levels of PGE2 and IL6 are associated with bone resorption and osteoclast recruitment and stimulation $[18,19]$. Bone matrix degradation occurs after decalcification by hydrochloric acid and the release of neutral matrix metalloproteinases (MMPs) from lysozomes. In vivo the cellular responses with the local cytokine and MMP expressions are dependent on the sampling site from the interface membrane and may be variable and show only focal expression within the periprosthetic tissue $[8,13]$.

Experimental models mimicking aseptic loosening as it occurs in clinical cases in human or canine patients are rarely described in the literature $[4,18,20-24]$. Most of the models favour the wear particles as the main cause of aseptic loosening and add them to the bone site at the initial time of surgery. Alternatively a model based on altering the biomechanics by purposely placing a loose implant [25]. These models prevent the study of the early changes found in a well-fixed total hip prosthesis because they don't simulate the real clinical situation. Recently a rat model was introduced where intensive exercise immediately after surgery initiated the formation of an interface membrane at the bone cement interface similar to the one observed in human patients [4]. This model seemed to give an explanation for early events in aseptic loosening, however, due to the rather excessive exercise regimen immediately after surgery may also not reflect the real clinical situation and may - for animal welfare reasons not be allowed to repeat in larger experimental animals.

Therefore, the goal of this study was to develop a new experimental animal model in sheep that reflects a more realistic clinical situation in humans (and also dogs) and allows to study the early biochemical changes at the bone cement interface in the time course of events. The model was based on a primary cement mantle defect on the femoral component of a hip prosthesis that was subsequently expected to trigger micromotion and initiate the cascade of cellular and biochemical events observed in clinical cases of aseptic loosening. Biochemical changes at the interface membranes were documented at two different time points.

Table I: Group distribution of experimental animals

\begin{tabular}{lll}
\hline Group & Number of animals & Time \\
\hline Group I: complete cement mantle & $N=6$ & 2 months \\
& $N=6$ & 8.5 months \\
Group II: primary cement mantle defect & $N=6$ & 2 months \\
& $N=6$ & 8.5 months
\end{tabular}




\section{Methods \\ Experimental animal model}

A total of 24 female Swiss alp adult sheep (age between 24 years), weighing from $45.2 \mathrm{~kg}$ to $90.1 \mathrm{~kg}$ (average 60.8 $\mathrm{kg})$, were divided in two groups $(\mathrm{n}=12)$, where Group I received a complete cement mantle and group II a cement mantle with a standardized primary defect. Groups I and II were further divided in two sub-groups based on time of euthanasia at 2 and 8.5 months (Tab. 1).

Immediately before surgery the sheep received prophylactically tetanus antiserum (Tetanus Serum, Veterinaria AG, Zurich Switzerland), $7 \mathrm{mg} / \mathrm{kg}$ gentamicin (Streuli \& Co AG, Switzerland) and 30'000 lU/kg penicillin G (Hoechst AG, Germany) intravenously. Anaesthesia was induced after sedation with medetomidine (5 $\mu \mathrm{g} \mathrm{mg/kg,} \mathrm{i.m.,}$ Domitor $^{\circledR}$, Orion-Farmos, Turku; Finland) with ketamine (2 mg/kg Narketan ${ }^{\circledast}$, Chassot AG, Switzerland) in combination with valium i.v. (Diazepam,0.01 mg/kg, Roche, Switzerland) and was maintained with Isoflurane (Forene $^{\circledR}$, Abbott AG, Baar, Switzerland) in 100\% oxygen. The antibiotic prophylaxis was continued for 5 days and an analgesic (Rimadyl ${ }^{\circledR}$ Carpofen, 4 mg/kg i.v., Pfizer Inc., NY, USA) was administered once a day for three days after surgery.

The sheep were randomly treated unilaterally with a total hip replacement using a cemented modular system (BioMedtrix, Allendale, NJ, USA). A routine craniolateral approach and total hip replacement procedure was performed to access the hip joint of the sheep and insert the hip prosthesis [26-28]. Briefly, the femoral head was luxated and the head removed at the femoral neck using a template. Care was taken to match the length of the femoral neck and the implant used. The femoral shaft was prepared using a broach. After meticulous cleansing of the bone marrow cavity and stopping of bleeding, slow, retrograde cement (Surgical Simplex P, Howmedica International Ltd, Limerick, Ireland) injection was performed into the bone cavity avoiding the formation of air bubbles. While the cement was still in the liquid phase, a size 9 (?) femoral component was introduced into the femoral shaft taking care achieving the correct position (anteversion) of the shaft. In Group I the prosthesis was fixed with retrograde cement gun injection in order to achieve a complete cement mantle (stable), whereas in group II (unstable) a primary cement mantle defect was produced using a small sized osteotome (Size 3, Aesculap, Tuttlingen, Germany) introduced at the lateral side of the femoral canal immediately after the liquid phase cement injection. Just before complete polymerization of the cement, the osteotome was removed leaving a standardized primary defect at the lateral site of the shaft at a $90^{\circ}$ angle to the femoral neck and extending the full length of the femoral component and $0.8 \mathrm{~mm}$ in width. After polymerization of the cement, the implant stability was assessed manually through the surgeon. All prostheses were stable despite the cement mantle defect in group II.

After surgery the sheep were confined in small stalls in groups of two sheep for 2-3 months. Thereafter, the animals of 8.5 months groups were transferred to larger stables where they were allowed to move free until the termination of the experiment. All animal experiments were conducted according to the laws of animal welfare in Switzerland (application number: 56/99).

\section{Sample collection and explant cultures}

The femora and the joint capsule of each operated limb were collected immediately after sacrifice of the animals. The bones were put on ice until further processing. Transverse bone sections were made of the femur with a special bone saw (Exakt System, Norderstedt, Germany). In order to get a good distribution and random selection of tissue samples throughout the femoral shaft, the sections were made according to five different regions. These regions were delineated with the aid of the same radiographic template used to determine the femoral implant size (R1 to R5) as described before (Fig 1). To facilitate sectioning of the bone slices, the femoral metal component within the cement mantle was carefully removed in a retrograde fashion. The first cut in the femur was placed immediately below the distal tip of the implant as measured by the template (Region 1-R1). Then, the femoral metal component was mobilized by placing an intramedullary Steinmann pin on the distal aspect of the stem while cautiously tapping with a hammer on the tip of the pin until the implant was freed from the cement mantle without breaking or loosening the bone cement itself. From each bone region, another bone slice was cut and split in half longitudinally such that the bone cement could be carefully removed and the interface membrane between the bone and the cement was exposed.

The interface membrane from each region was carefully harvested with the aid of a curette. Half of this material was immediately used for explant cultures, while the other half was frozen in liquid nitrogen for mRNA determination. The sample from each region was cultured separately to obtain a representative distribution of the whole femoral shaft.

The explant cultures were carried out in 24 well plates. Briefly, tissue specimens were trimmed weighed (50 mgtissue/-explant culture) and washed in Gey's balanced salt solution (Gibco Life Technologies, Basel, Switzerland). The tissue was placed into these wells in the presence of 3 ml Ham's F12 nutrient medium containing 1\% of penicillin (100 units $/ \mathrm{ml})$ and streptomycin $(100 \mu \mathrm{g} / \mathrm{ml})$ (Fluka, Buchs, Switzerland). Cultures were incubated for 48 hours 

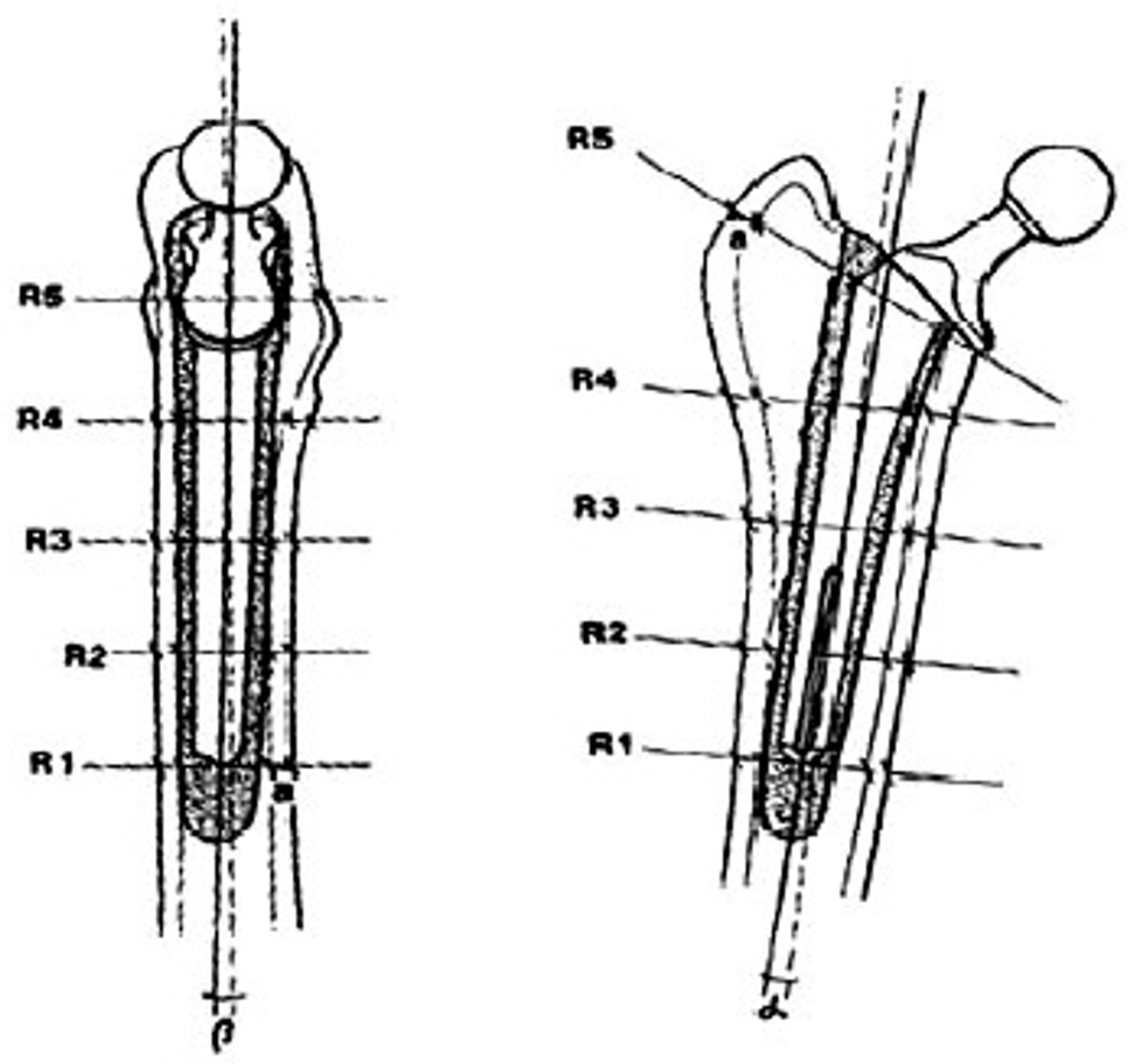

Figure I

Template of the femur with implanted prosthesis. Schematic drawing of the femoral implant within the femur showing the regions were sections were made and samples were harvested (RI-R5).

at $37^{\circ} \mathrm{C}$ in a $5 \% \mathrm{CO}_{2}$ and $\mathrm{H}_{2} \mathrm{O}$ saturated atmosphere. After this period, $3 \mathrm{ml}$ of supernatant was carefully collected from each well; divided in 5 aliquots and finally all samples were frozen at $-20^{\circ} \mathrm{C}$ until used for the assays. The same procedure was performed for the joint capsule (JC) of the operated femora.

\section{Biochemical assays}

All samples were run in duplicates.
Nitric oxide determinations

The release of NO was assessed using the Griess reaction [29]. This reaction is based on a spectrophotometric method where nitrite is measured as a stable end product of NO representing $51.5 \pm 3.5 \%$ of total $\mathrm{NO}$ [30]. The reaction of naphtylenediamine dihydrochloride $(0,1 \%)$ and sulfanilamide $(0.1 \%)$ in o-phosphoric acid in combination with nitrite results in a red-brownish color of which the colorimetric density can be measured at 550 $\mathrm{nm}$ wavelength in a microplate reader. 


\section{PGE2 determinations}

A commercially available $\mathrm{PGE}_{2}$ Immunoassay (R\&D Systems, Oxon, England) was used as validated in sheep before [31]. Briefly, this kit is a competitive assay in which the $\mathrm{PGE}_{2}$ present in the sample competes with a fixed amount of alkaline phosphatase-labeled $\mathrm{PGE}_{2}$ for sites on a mouse monoclonal antibody that is bound to a 96-well microplate with a goat anti-mouse antibody. The analysis of all samples was performed in duplicates. Standard concentrations of PGE2 were run with a range of $0-5000 \mathrm{pg} /$ $\mathrm{ml}$. Some of the samples had to be diluted due to the high concentrations that were not within the sensitivity range of the standard concentrations. The determination of the optical density of each well was done using a microplate reader set to $450 \mathrm{~nm}$ with wavelength correction set between $570 \mathrm{~nm}$ and $590 \mathrm{~nm}$. The intensity of the colour of each well is inversely proportional to the concentration of $\mathrm{PGE}_{2}$ in the sample.

\section{Activity of neutral metalloproteinases}

Collagenolytic and caseinolytic activities were determined using an assay based on radiolabelled substrates ( ${ }^{3} \mathrm{H}$-acetic anhydride, New England Nuclear, Boston, MA, USA) [32]. Collagen type I (Vitrogen ${ }^{\circledR}$, Collagen GmbH, Ismaning, Germany) was used as a substrate for collagenolytic activity. Lyophilized casein served as substrate for detecting caseinolytic activities. All substrates were dialyzed with a ${ }^{3} \mathrm{H}$-acetic anhydride labeled reaction buffer containing $30 \mathrm{mM}$ Tris- $\mathrm{HCl}, 0.2 \mathrm{M} \mathrm{NaCl}$ and $5 \mathrm{mM} \mathrm{CaCl}_{2}$ and adjusted to $\mathrm{pH}$ 7.4. The substrates were adjusted to a 1000 $\mathrm{cpm} / \mu \mathrm{g}$ in the scintillation counter. Trypsin $(10 \mu \mathrm{g})$ was used as a positive control for caseinolytic activities and bacterial collagenase (10 $\mu$ ) for collagenolytic activity.

A solution of $20 \mu \mathrm{l}$ of reaction buffer, $10 \mathrm{mul}$ of aminophenylmercuric acetate (APMA), $20 \mu$ l of conditioned media and $25 \mu \mathrm{l}$ of labeled substrate was used for assessing collagenolytic activity. APMA was added to the samples to activate any latent form of neutral metalloproteinases. The mixtures were incubated at $30^{\circ} \mathrm{C}$ for 4 hours. The reaction was stopped by adding $10 \mu \mathrm{l}$ of o-phenanthroline in 50\% p-dioxane diluted with reaction buffer. The tubes were incubated for another hour at $35^{\circ} \mathrm{C}$. Undigested collagen fibrils were precipitated with $75 \mu \mathrm{l}$ of p-dioxane and centrifuged at $12000 \times \mathrm{g}$ for 10 minutes. Radioactivity of $50 \mu \mathrm{l}$ was determined by liquid scintillation.

For detection of caseinolytic activities a solution with 20 $\mu \mathrm{l}$ of reaction buffer, $10 \mu \mathrm{l}$ of APMA, $20 \mu \mathrm{l}$ of conditioned media and $20 \mu \mathrm{l}$ of labeled casein were made. The mixture was incubated for 4 hours at $37^{\circ} \mathrm{C}$. The termination of the reaction was done by addition of $100 \mu \mathrm{l}$ of $6 \%$ trichloracetic acid and $50 \mu \mathrm{l}$ of cold casein as a carrier for the assay. Mixtures were centrifuged at $12000 \times \mathrm{g}$ for 10 minutes.
Radioactivity of $100 \mu \mathrm{l}$ supernatant of casein was determined by liquid scintillation. Calculations for the activity for each assay were based on the assumption that $1 \mathrm{U}$ of enzyme degrades $1 \mu \mathrm{g}$ of substrate per minute.

\section{RNA extraction}

Interface membrane samples conserved at -80C were submitted to a procedure described by Nemeth at al. [33]. Briefly, samples were aseptically handled and put into a guanidinethiocyanate solution and homogenized. After short centrifugation the supernatant was removed and transferred to ultracentrifuge tubes containing $1.2 \mathrm{ml}$ of a 5.7 $\mathrm{M}$ cesium chloride solution. These tubes were ultra centrifuged for 15-17 hours with $35000 \mathrm{rpm}$ at $18^{\circ} \mathrm{C}$. The precipitate formed at the bottom of these tubes was carefully manipulated and the supernatant removed. The pellet was eluted and washed several times using different steps with chloroform-butanol, ethanol 100\%, sodium acetate solution and ethanol 70\%. Finally the pellets were dried at room temperature under a lamp. The pellets were eluted with RNA-se free water and total RNA was quantified on the spectrophotometer. The extracted RNA was conserved at $-80 \mathrm{C}$.

\section{$R N A$ reverse transcription}

The first strand cDNA from the total RNA was synthesized with the Superscript Preamplification System (Gibco Life Technologies, Basel, Switzerland). The samples were prepared with Oligo $(\mathrm{dT})_{12-18}$ and incubated for $10 \mathrm{~min}$. at $70^{\circ} \mathrm{C}$. The master mix was prepared and added to each tube. The tubes were incubated for 5 minutes at $42^{\circ} \mathrm{C}$. At this point $1 \mu \mathrm{l}$ of the Superscript Reverse transcriptase was added to each tube. The tubes were incubated for $50 \mathrm{~min}$ at $42^{\circ} \mathrm{C}$. The reactions were terminated at $70^{\circ} \mathrm{C}$ for 15 min and the tubes chilled with ice. The content of the tubes was brought down by brief centrifugation. One $\mu$ l of Rnase was added to each tube and incubated for $20 \mathrm{~min}$ at $37^{\circ} \mathrm{C}$. The tubes containing cDNA were conserved at $20 \mathrm{C}$.

\section{Real-Time polymerase chain reaction (PCR)}

The quantitative real time PCR was performed according to an established procedure using the TaqMan system [34] (PCR, ABI 7700, PE Applied Biosystems, Rotkreuz, Switzerland). The tubes containing the cDNA were used in the TaqMan real time PCR with primer pairs for standard amplification. For this procedure glyceraldehyde-3 phosphate dehydrogenase $\left(\mathrm{GAPDH}\right.$; forward primer $5^{\prime}$ TGGGCGTGAACCACGAG-3', reverse primer 5'-AGTCCCTCCACGATGCCA-3'), inducible nitric oxide synthase (iNOS; forward primer 5'-TGACTTTCCAAGACACGCTTCA-3', reverse primer 5'-ACTTTTGGGATTCATGATGGATG-3'), cyclooxygenase-2 (COX-2; forward primer 5'CATGCCGAATCGAGGTGTATGTA-3', reverse primer 5'CGGGAGTGGGTTTCAGGAGT-3'), interleukin $1 \beta$ (IL-1 $\beta$; 
Table 2: Mean concentrations (NO, PGE2) and neutral metalloproteinases activity. Note high standard deviations in all groups.

\begin{tabular}{lcccc}
\hline Lab.value & Group I 2 months & Group I 8.5 months & Group II 2 months & Group II 8.5 months \\
\hline NO $\mu$ Mol) & $24.28 \pm 16.9$ & $175.33 \pm 225.0$ & $40.1 \pm 44.9$ & $235.31 \pm 236.5$ \\
PGE2 (pg/L) & $0.73 \pm 1.7$ & $298.9 \pm 324.3$ & $1.4 \pm 1.7$ & $1066.39 \pm 3717.4$ \\
Collagenolytic activity (IU/L) & $0.001 \pm 0.0$ & $0.04 \pm 0.1$ & $0.3 \pm 1.6$ & $0.17 \pm 0.3$ \\
Caseinolytic activity (IU/L) & $0.32 \pm 0.2$ & $0.04 \pm 0.1$ & $0.52 \pm 0.1$ & $0.06 \pm 0.1$ \\
\hline
\end{tabular}

forward primer 5'-ATGAGCTGTTATTTGAGGTTGATGG3', reverse primer 5'-TGAGAAATCTGCAGCTGGATGT-3'), interleukin 6 (IL-6; forward primer 5'-TCAGCTTATTTTCTGCCAGTGTCT-3', reverse primer 5'-TCATTAAGCACATCGTCGACAAA) and oligonucleotide probes with a fluorescent reporter dye (6-carboxy fluorescein-FAM) and a quencher dye (6-carboxy-tetramethyl-rhodamine) were used. The probes for the TaqMan for GAPDH, iNOS, COX-2, IL-1 $\beta$, IL-6 were 5'-FAM-3', 5'-FAM-AGAAGGCCAAAGGGGATCTCTCCTGCA-3', 5'-FAMTGAAAACTGTACACCTGAATTTCTGACAAGA-3', 5'-, respectively.

The primers and probes were made according to published sequences. TaqMan real time PCR was carried out using the ABI Prism 7700 and started by a hot start PCR amplification set at $95^{\circ} \mathrm{C}$ and the annealing period was of $1 \mathrm{~min}$ at $60^{\circ} \mathrm{C}$. Forty five PCR cycles were allowed to measure the development of the reporter dye. The threshold cycle values, based on a constructed standard curve, were used to determine the amount of target cDNA (iNOS, COX-2, IL-1 $\beta$, and IL-6) and the internal control cDNA $(\mathrm{GAPDH})$. Threshold cycle $\left(\mathrm{C}_{\mathrm{T}}\right)$ is defined as the PCR cycle where a raise in reporter fluorescence over a baseline signal can first be detected.

\section{Statistics}

The data of the different regions (R1-5) and capsule tissue (JC) were collected individually for each region, but for statistical evaluation thereafter the results were pooled for each bone. Overall differences between groups (stable vs. unstable) and time periods (2 vs.8.5 months) and interactions thereof were calculated using a factorial analysis of variance (ANOVA) (Statview, Cary, NC, USA). Correlation coefficients were calculated and using z-transformation levels of significance were determined (P-values < 0.05).

\section{Results}

The formation of an interface membrane was demonstrated in both, the one group with the complete and the other with the cement mantle with the primary defect. However, the interface membrane of both groups differed in thickness as well as its presence at the two time points.
In the 2 months groups, the interface membranes were similar in thickness although there was a tendency for the group II with the primary cement mantle defect to be thicker and more variable between the regions. Furthermore, the capsule that developed around the femoral neck was thicker compared to the stable group I. In the 8 months groups, the interface membrane of the group with the complete cement mantle had mostly regressed and only in the most distal region (1R-1) seemed to be thicker compared to the other regions. In contrast, the group with the primary cement mantle defect showed a definite thicker interface membrane at 8.5 months in all regions and in $70 \%$ cases, the implant was already loosened and could easily be pulled out. Despite an already loose implant clinical lameness could not be detected in the animals before they were sacrificed. In most cases, the amount of tissue obtained was sufficient for performing explant cell cultures and further biochemical analysis. However, in some cases (especially in the stable group) not enough membrane material could be harvested for tRNA extraction.

\section{Biochemical analysis (see Tab. 2)}

Nitric oxide concentrations (Fig. 2)

Mean concentrations of NO varied significantly between tissues harvested at 2 and 8 months $(P<0.0001)$, but not between the group I with the complete cement mantle and the group II with the primary defects. Nevertheless, there was a tendency to have a higher concentration in the group with the primary cement mantle defect. In all groups standard deviations were very high.

\section{Prostaglandin E2 concentrations (Fig. 3)}

$\mathrm{PGE}_{2}$ analysis revealed differences in concentrations over time but just missed statistical significances $(P=0.058)$. If the stable groups I were compared at 2 and 8 months statistical significant differences were found $(P=0.0002)$, which was not the case in the group II with the primary cement mantle defect $(\mathrm{P}=0.09)$. The same was true if both groups were compared at $2(\mathrm{P}=0.18)$ and 8.5 months $(P=0.27)$, however, there was a tendency for the groups II with the primary cement mantle defect to show higher concentrations. As with NO, standard deviations were very high. 


\section{NO concentrations}

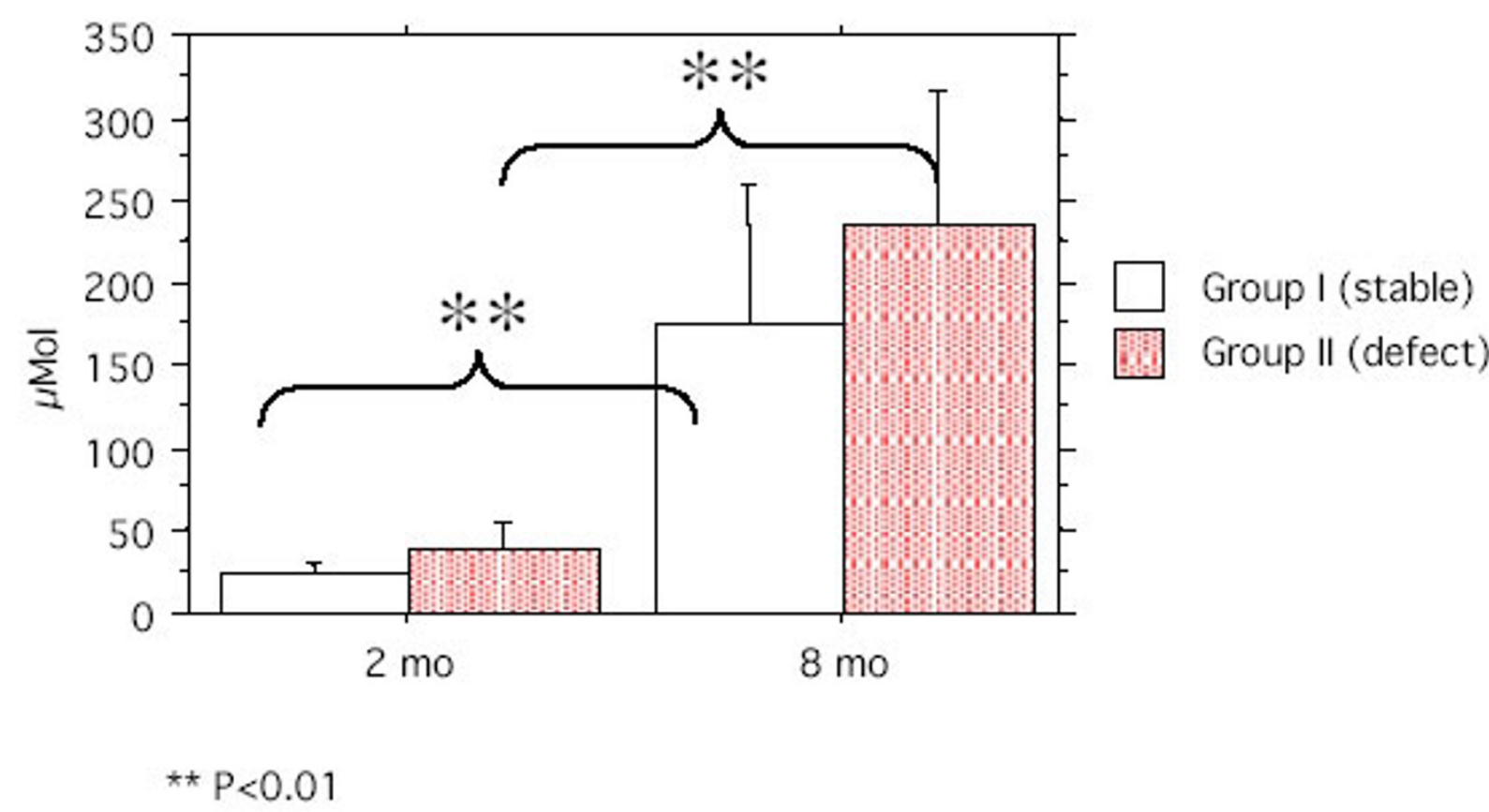

Figure 2

Graph with NO concentrations and indication of statistical significances. Note that concentrations increased considerably in the 8 months group.

\section{Neutral metalloproteinases activity (Fig. 4 \&5)}

Overall differences of collagenolytic activity in media from tissue samples of interface membranes were not significant, although there was a tendency for the group II with the primary cement mantle defect to show higher values at 2 months and decrease over time. Significant differences were demonstrated between the 2 groups at 8 months, where the group II with the primary cement mantle defect showed higher activities $(P=0.04)$. Statistical significant differences were recorded for caseinolytic activities over time such that activities were higher at 2 months for the stable group I compared to all other groups $(\mathrm{P}=$ $0.002)$. Individual differences between groups were significant at $2(P<0.0001)$, but not at $8(P=0.7)$ months.

\section{qRT-PCR (Tab. 3)}

The results obtained with the qRT-PCR were non-conclusive (Tab. 3). The internal GAPDH control values were already difficult to obtain indicated by a relative high cycle numbers for mRNA detection (27-33 cycles).
Although mRNA could be detected for IL-1, IL-6, iNOS and cox-2 in some of the samples, mean cycle numbers were very high and thus, have to be interpreted with caution. mRNA of iNOS and IL- 6 were detected in almost all samples, while IL-1 and PGE2 were found in only very few samples.

\section{Correlations (Tab. 4)}

Significant positive correlations were found for $\mathrm{NO}$ and collagenolytic activities at $2(\mathrm{P}=0.005)$ and $8(\mathrm{P}=0.02)$ months in the stable, and in the group with the primary cement mantle defect at 8 months $(P=0.0009)$. The same was true for NO and caseinolytic activities at 8 months ( $P$ $<0.0001)$, collagenolytic and caseinolytic activities at 2 months $(\mathrm{P}=0.014)$, as well as PGE2 and collagenolytic activities at 2 months $(\mathrm{P}<0.0001)$. All other correlations were not significant. However, tendencies for negative correlations were found for all other groups between $\mathrm{NO}$ and PGE2, PGE2 and collagenolytic activities and colla- 


\section{PGE2 concentrations}

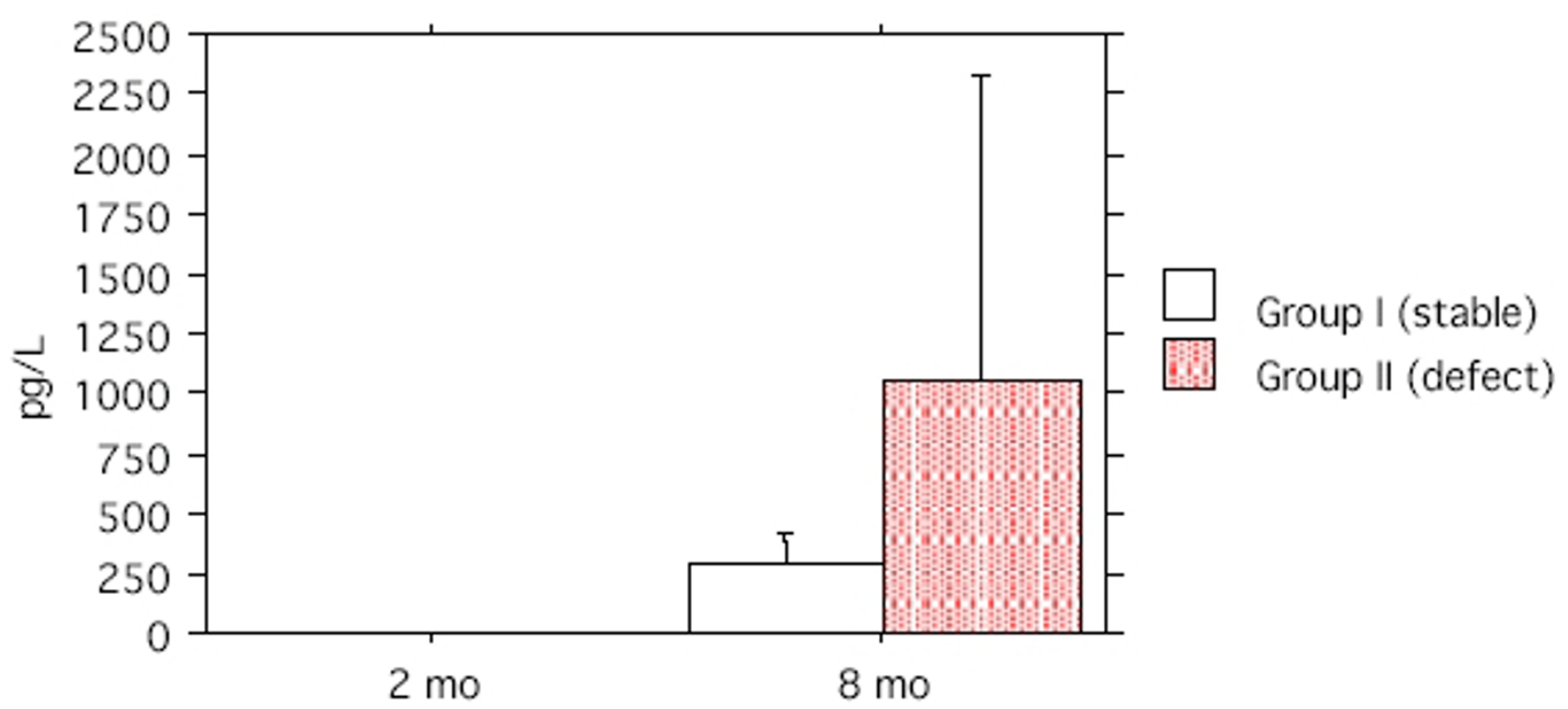

Figure 3

Concentrations of PGE2 at 2 and 8 months. Statisticalsignificances were not demonstrated due to high standard deviations.

genolytic and caseinolytic activities. For PGE2 and caseinolytic activities all groups showed a tendency for positive correlations.

\section{Discussion}

The experimental animal model with the primary cement mantle defect enabled to follow the formation of an interface membrane between bone and cement over time, as well as to study early biochemical changes within the interface tissue. There were biochemical differences between the stable controls and the groups with the primary cement mantle defect such that the concentration of the local mediators NO and PGE2 was elevated in the group with the primary cement mantle defect and increased in the time course over 2 and 8 months. The collagenolytic activity was highest in the group with the primary cement mantle defect at 2 months, but stayed relatively stable throughout the rest of the study. Caseinolytic activity was highest in the control group and decreased over time. Positive correlations were found between NO and PGE2 concentrations and also in the 2 months groups for NO, PGE2 and the activity of the neutral metalloproteinases.
Problems that arose from our experimental model in conjunction to surgery were related to the standardization of the surgical technique and post-operative management of the sheep. The two fractures could have probably been prevented with strict confinement in small boxes or by using a suspension system in the first two weeks after surgery. One of the difficulties of the model was to ensure the repeatability of the cement mantle. Despite the use of new cementing techniques (pressurization, retrograde cement injection), the cement plug, the centralizer and the vacuum cement mixer were not available at the time of the surgical procedures. These devices would most likely produce a more uniform cement mantle [35-38] and thus, also a standardized defect. However, a recent twenty year follow-up study using Charnley total hip arthroplasty with these contemporary cement techniques showed no significant clinical outcome improvement related to aseptic loosening using these new assets [39]. Therefore, it is reasonable to assume that the outcome would have been similar also in our experimental animals model. Throughout the experiment the same size of osteotome and surgical technique was used. All surgeries were performed by the same, very experienced surgeon (Olm- 


\section{Collagenolytic activity}

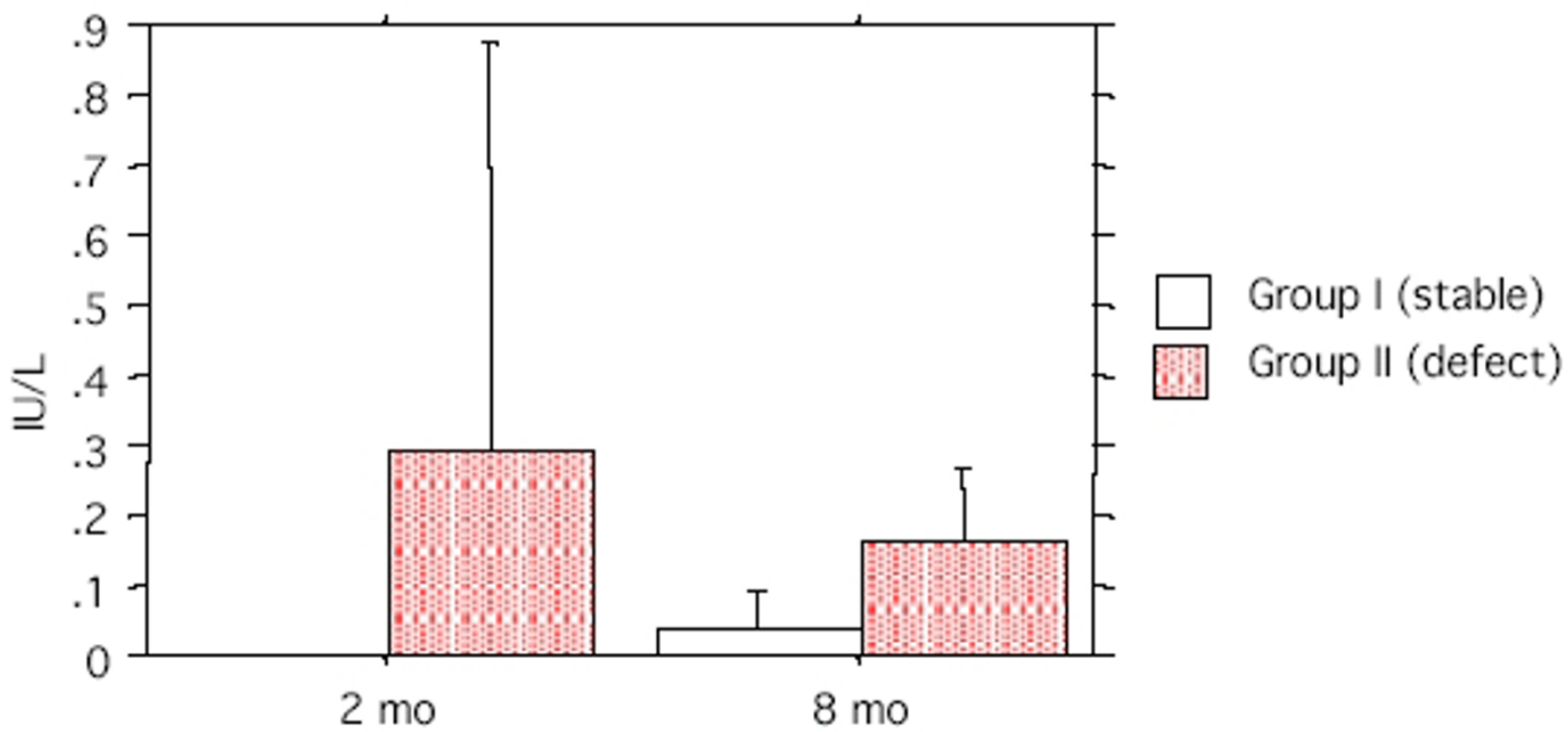

Figure 4

Cllagenolytic activity of neutral metalloproteinases in cell culture media decreased over time with a tendency to be higher in the group with the primary cement mantle defect.

stead), who created the defect by inserting the osteotome parallel to the femoral shaft at the exact same depth. Therefore, it is safe to assume that the standardisation of the defect was as accurate as possible. The development of an interface membrane in the most distal (R1) and proximal region corresponded to the points of maximum shear stress demonstrated with three-dimensional finite element analysis in cemented hip prosthesis for dogs [40].

Another problem occurred with the quantitative RT-PCR, where it was difficult to detect mRNA levels. Normally cycle numbers to detect GAPDH vary between $20-24$ cycles in our laboratory and depending on tissue differ little between samples. In this study, however, cycle numbers were very high also for the internal control indicating that difficulties were present isolating tRNA from tissue samples (the higher cycle numbers, the less mRNA is present). Although the procedure was repeated 2-3 times (depending on availability of tissue), the detection limit could not be improved. This was reflected also with the numbers of cycles for IL-1, IL-6, iNOS and cox-2, although mRNA of IL- 6 and iNOS were at least detected in most of the groups. The fact that mRNA levels of cox- 2 could only be detected in the 2 months control group despite the high concentrations of PGE2 in the 8 months samples, lead to the conclusion that technical problems were responsible for these results. Interface tissue samples are rich in collagen fibres but depending on localization low in cell numbers. The latter was confirmed by histology (unpublished data). The thicker the interface membrane, the more collagen fibres were present and the lower were cell numbers. It is likely that samples did not contain enough cells to isolate sufficient total mRNA for later detection of cox- 2 or also IL- 6 . With the tissue in cell cultures for several days, it could also be that the ubiquitous mRNAse may have destroyed the mRNA within the cells before it could be isolated. Nevertheless, IL- 6 and iNOS both were detected and confirm findings in other studies dealing with local cytokine [5] and mediator [41] upregulation

High standard deviations were recorded in all concentrations of both local mediators (NO, PGE2) and neutral metalloproteinase activity, more so than usually found in our laboratory data. Since all samples were run in duplicates and in most cases were repeated, the deviations can- 


\section{Caseinolytic activities}

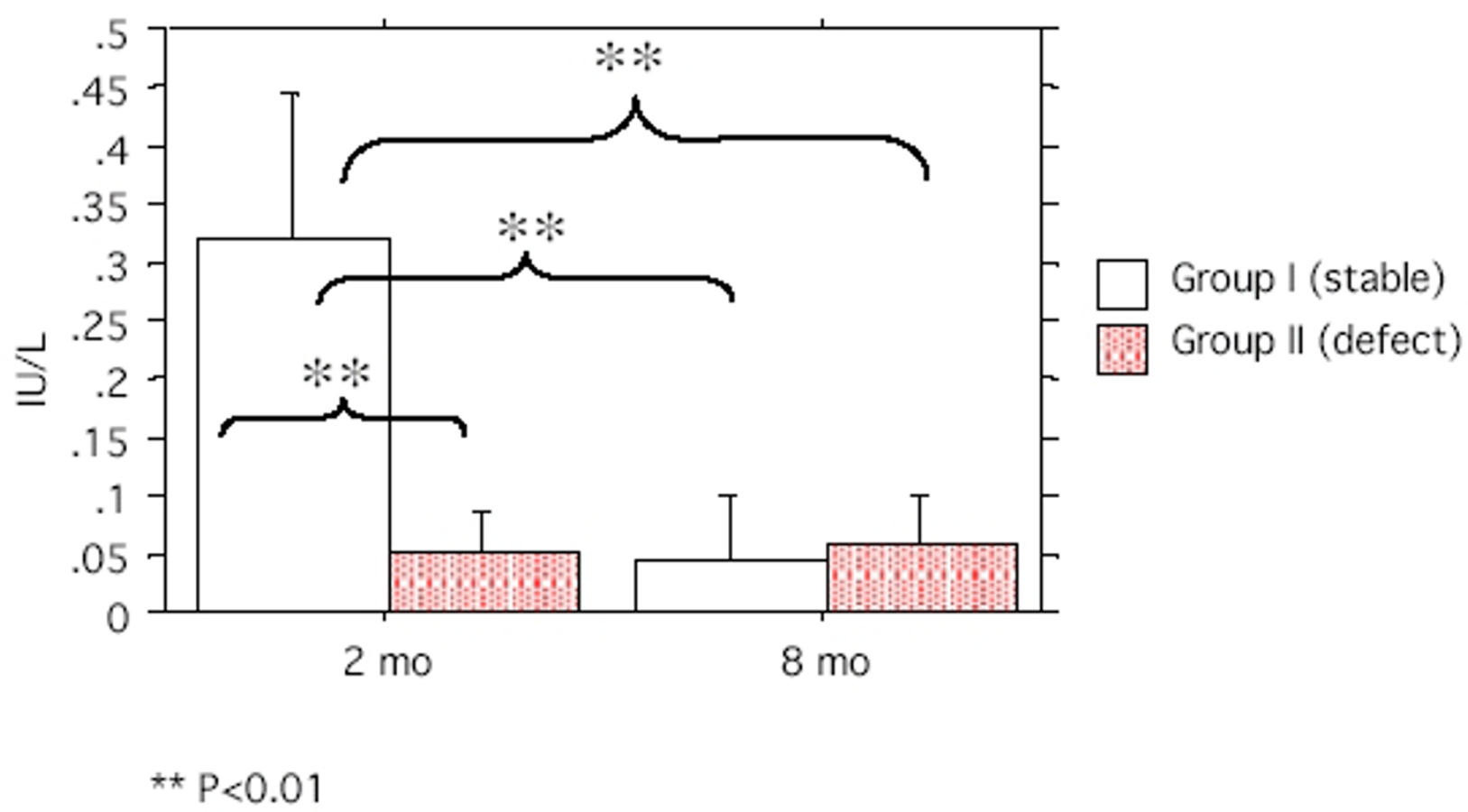

\section{Figure 5}

Caseinolytic activity in cell culture media of tissue from interface membranes was highest in the stable group at 2 month and decreased over time. Differences were significant for all groups.

Table 3: quantitative mRNA detection (qRT-PCR) of IL-I, IL-6, iNOS and cox-2 using the TaqMan system. Negative values most likely represent technical difficulties in isolating mRNA of the tissue.

\begin{tabular}{|c|c|c|c|c|c|}
\hline Expression & GAPDH & IL-I & IL-6 & iNOS & PGE2 \\
\hline Stable 2 months & 32.5 & 0 & 36 & 0 & 0 \\
\hline Cement mantle defect 2 months & 27 & 0 & 40 & 32 & 35 \\
\hline Stable 8.5 months & 33 & 0 & 0 & 40 & 0 \\
\hline Cement mantle defect 8.5 months & 29 & 33 & 35 & 35 & 0 \\
\hline
\end{tabular}

not be attributed to technical or quality problems of the laboratory practice. They rather reflect the local differences within the regions and the focal expression of the mediators and enzyme activity along the femoral shaft. If values of the different regions were compared individually, the deviations were generally less but due to small sample numbers were also not statistically more significant (unpublished data). In any case, concentrations of NO and PGE2 were high and increased over time in this experiment. These observations were in accordance with some studies reported in the literature that showed that both NO and PGE2 are associated with the induction and maintenance of the chronic inflammatory reaction $[10,11]$. The high levels of PGE2 could be attributed to the high concentrations of NO in both groups. Some authors have shown that NO can induce and regulate the synthesis of cyclooxygenase 2 (cox-2), the enzyme responsible for production of PGE2 in osteoblasts [42]. However, other 
Table 4: Statistically significant correlations found between concentrations of local mediators (NO, PGE2) and enzymatic activities of neutral metalloproteinases. Note that NO and PGE2 concentrations show a positive correlation.

\begin{tabular}{llll}
\hline Groups & Variables & Correlation coefficient & P-value \\
\hline Group I: 2 months & NO, collagenolytic activity & 0.608 & 0.004 \\
Group I: 8 months & NO, collagenolytic activity & 0.415 & 0.024 \\
Group II: 8 months & NO, collagenolytic activity & 9.522 & 0.009 \\
Group I: 8 months & NO, caseinolytic activity & 0.661 & $<0.000$ I \\
Group II: 2 months & PGE2, collagenolytic activity & 0.704 & $<0.000$ I \\
Group I: 2 months & Collagenolytic, caseinolytic activity & 0.56 & 0.014 \\
\hline
\end{tabular}

authors have demonstrated a more negative correlation between those two mediators. It was shown that low concentrations of $\mathrm{NO}$ were associated with higher concentrations of PGE2, while high concentrations of NO seemed to lower PGE2 concentrations [43]. In this study, the concentrations of both local mediators were increased at 8.5 months after surgery compared to the 2 months group similar to preliminary investigation with the same experimental model in dogs [44] and confirming that these local mediators play an active ole in the process of aseptic loosening and development of interface membrane in conjunction with a mechanically challenged hip prosthesis. The high levels of NO and PGE2 concentrations corroborate clinical findings in vitro $[16,45]$ and in human patients with aseptic loosening where high levels of precursor enzymes of PGE2 and NO (COX-2 and iNOS) in the tissues macrophages of these tissues were demonstrated [11]. Early bone resorption could be associated with the high levels of PGE2, which is a known potent inflammatory agent and is paramount in recruiting osteoclasts in combination with IL-6 $[18,45,46]$.

The activity of neutral metalloproteinases is thought to be indicative of the activities of several matrix metalloproteinases. While earlier it was thought that collagenolytic activity could be attributed to collagenases and caseinolytic activities to stromelysin, it was shown meanwhile that mainly collagen can be degraded by several neutral metalloproteinases (MMP1,8,13, MT-1) $[47,48]$. Therefore, the attempt was made to support this data with measurements of the MMP1 and MMP3 mRNA levels from tissue of the interface membrane. As explained above, this was only partially achieved. Nevertheless, the relatively high caseinolytic and collagenolytic activity found in our studies could well be related to the initial inflammatory reaction caused by the surgical trauma more evident after 2 months. This was more pronounced in the control group at least for caseinolytic activities. Our laboratory has previously shown that at least initially, high levels of PGE2 could be potentially associated with the inhibition of the enzymatic activity of MMP3, but over time, the activity of stromelysin increased parallel to the rising concentration of PGE2 in vitro $[43,44]$. This was not the case in this study at least for caseinolytic activities. Unfortunately, mRNA levels of the relevant MMP mRNA could not be determined in this study due to the fact that probes for sheep were not available at the time of the experiments. This may have revealed different results compared to caseinolytic activities that may be influenced by inhibitors within the tissue $[47,48]$. In one study measuring the mRNA expression of metalloproteinases in interface membranes retrieved from aseptic loosened prostheses in humans, MMP3 was highly expressed in the tissues associated with bone resorption [13]. This was also true for the mRNA expression of interstitial collagenase (MMP-1) that has been regularly detected in the interface membrane of patients with aseptic loosening [13]. Meanwhile high mRNA expressions of MMP1 and MMP3 were also found with a similar experimental animal model in our laboratory mimicking aseptic loosening of titaniumaluminum-vanadium implants in sheep [49].

\section{Conclusions}

The experimental animal model where cemented hip prosthesis were implanted with a primary cement mantle defect in sheep lead to early biochemical changes at the implant bone interface that may be triggering the cascade of aseptic loosening of the metal implant. Although this animal model in sheep is not equivalent to the clinical condition of aseptic loosening in human patients, it may allow time course studies at the bone implant interface in the future and help to elicit the role of biomechanical stability, different cell types, cytokines and enzymes and their interactions in the early cascade of aseptic loosening in the future.

\section{Competing interests}

There are no competing interests on this study

\section{Authors' contribution}

AEW was the PhD student on the project and was involved in all activities concerning the project

$\mathrm{MO}$ was the main surgeon for the experimental surgeries 
RS and did part of the molecular work

LM was the main scientist on the molecular work

RBW was the anaesthetist during surgeries

MA contributed to the medical care of the animals

JA helped in designing the project and writing the manuscript

BvR designed the project and was the leader as well as the histologist of the project

\section{Acknowledgements}

The authors thank CNPq, Brazil for providing the salary through the grant 200430/97-I. We also thank Prof. Ann Johnson (Surgery Dept. Faculty of Veterinary Medicine, University of Illinois) for reviewing the English manuscript.

\section{References}

I. Goldring SR, Schiller AL, Roelke M, Rourke CM, O'Neil DA, Harris WH: The synovial-like membrane at the bone-cement interface in loose total hip replacements and its proposed role in bone lysis. J Bone Joint Surg [Am] 1983, 65:575-584.

2. Xu JW, Konttinen YT, Lassus J, Natah S, Ceponis A, Solovieva S, Aspenberg P, Santavirta S: Tumor necrosis factor-alpha (TNFalpha) in loosening of total hip replacement (THR). Clin Exp Rheumatol 1996, 14:643-648.

3. Aspenberg P, Van der Vis H: Migration, particles, and fluid pressure. A discussion of causes of prosthetic loosening. Clin Orthop 1998:75-80.

4. Pap G, Machner A, Rinnert T, Horler D, Gay RE, Schwarzberg H, Neumann W, Michel BA, Gay S, Pap T: Development and characteristics of a synovial-like interface membrane around cemented tibial hemiarthroplasties in a novel rat model of aseptic prosthesis loosening. Arthritis Rheum 200I, 44:956-963.

5. Goodman SB, Huie P, Song Y, Schurman D, Maloney W, Woolson S, Sibley R: Cellular profile and cytokine production at prosthetic interfaces. Study of tissues retrieved from revised hip and knee replacements. J Bone Joint Surg Br 1998, 80:531-539.

6. Jiranek WA, Machado M, Jasty M, Jevsevar D, Wolfe HJ, Goldring SR, Goldberg MJ, Harris WH: Production of cytokines around loosened cemented acetabular components. Analysis with immunohistochemical techniques and in situ hybridization [see comments]. J Bone Joint Surg Am 1993, 75:863-879.

7. Chiba J, Rubash HE, Kim KJ, Iwaki Y: The characterization of cytokines in the interface tissue obtained from failed cementless total hip arthroplasty with and without femoral osteolysis. Clin Orthop 1994:304-3I2.

8. Goodman SB, Knoblich G, O'Connor M, Song Y, Huie P, Sibley R: Heterogeneity in cellular and cytokine profiles from multiple samples of tissue surrounding revised hip prostheses. J Biomed Mater Res 1996, 31 : 421-428.

9. Konttinen YT, Kurvinen H, Takagi M, Michelsson JE, Eklund KK, Nordsletten L, Buo L, Aasen AO, Santavirta S: Interleukin-I and collagenases around loosening total hip prostheses. Clin Exp Rheumatol 1996, 14:255-262.

10. Watkins SC, Macaulay W, Turner D, Kang R, Rubash HE, Evans $\mathrm{CH}$ : Identification of inducible nitric oxide synthase in human macrophages surrounding loosened hip prostheses. $\mathrm{Am} J$ Pathol 1997, I 50: I 199- I206.

II. Hukkanen M, Corbett SA, Batten J, Konttinen YT, McCarthy ID, Maclouf J, Santavirta S, Hughes SP, Polak JM: Aseptic loosening of total hip replacement. Macrophage expression of inducible nitric oxide synthase and cyclo-oxygenase-2, together with peroxynitrite formation, as a possible mechanism for early prosthesis failure. J Bone Joint Surg Br 1997, 79:467-474.
12. Hembry RM, Bagga MR, Reynolds J], Hamblen DL: Stromelysin, gelatinase $A$ and TIMP-I in prosthetic interface tissue: a role for macrophages in tissue remodelling. Histopathology 1995, 27:149-159.

13. Ishiguro N, Ito T, Kurokouchi K, Iwahori Y, Nagaya I, Hasegawa $Y$, Iwata $\mathrm{H}$ : mRNA expression of matrix metalloproteinases and tissue inhibitors of metalloproteinase in interface tissue around implants in loosening total hip arthroplasty. J Biomed Mater Res 1996, 32:61 I-617.

14. Takei I, Takagi M, Santavirta S, Ida H, Hamasaki M, Ishii M, Fukushima $S$, Ogino T, Konttinen YT: Matrix metalloproteinases and tissue inhibitors of metalloproteinases in joint fluid of the patients with loose artificial hip joints. J Biomed Mater Res 1999, 45: $175-183$.

15. Takei I, Takagi M, Santavirta S, Ida H, Ishii M, Ogino T, Ainola M, Konttinen YT: Messenger ribonucleic acid expression of 16 matrix metalloproteinases in bone-implant interface tissues of loose artificial hip joints. J Biomed Mater Res 2000, 52:613-620.

16. Horowitz SM, Purdon MA: Mechanisms of cellular recruitment in aseptic loosening of prosthetic joint implants. Calcif Tissue Int 1995, 57:301-305.

17. Wang W, Ferguson DJ, Quinn JM, Simpson AH, Athanasou NA: Osteoclasts are capable of particle phagocytosis and bone resorption. J Pathol 1997, 182:92-98.

18. Thornhill TS, Ozuna RM, Shortkroff S, Keller K, Sledge CB, Spector $M$ : Biochemical and histological evaluation of the synoviallike tissue around failed (loose) total joint replacement prostheses in human subjects and a canine model. Biomaterials 1990, II:69-72.

19. Sun J, Tsuang Y, Lin F, Liu H, Tsai C, Chang W: Bone defect healing enhanced by ultrasound stimulation: An in vitro tissue culture model. J Biomed Mater Res 1999, 46:253-26I.

20. Spector M, Shortkroff S, Hsu HP, Taylor-Zapatka S, Lane N, Sledge CB, Thornhill TS: Synovium-like tissue from loose joint replacement prosthesis: comparison of human material with a canine model. Semin Arthritis Rheum 1992, 21:335-344.

21. Goodman S, Aspenberg $P$ et al:: The effects of particulate cobalt chrome alloy and high density polyethylene on tissue ingrowth into bone harvest chamber in rabbits. In: 40th Annual Meeting of the Orthopedic Research Society New Orleans, Louisiana, USA; 1994:840.

22. Dowd JE, Schwendeman LJ, Macaulay W, Doyle JS, Shanbhag AS, Wilson $\mathrm{S}$, Herndon JH, Rubash HE: Aseptic loosening in uncemented total hip arthroplasty in a canine model. Clin Orthop 1995:106-121.

23. Lalor $P$ et al.: Early osteolysis in a stable canine model of aseptic implant loosening. In: 44th Annual Meeting of the Orthopedic Research Society New Orleans, Louisiana, USA; 1998:789.

24. Kadoya $\mathrm{Y}$, Kobayashi A, Ohashi $\mathrm{H}$ : Wear and osteolysis in total joint replacements [see comments]. Acta Orthop Scand Suppl 1998, 278: I- 16.

25. Turner TM, Urban RM, Sumner DR, Galante JO: Revision, without cement, of aseptically loose, cemented total hip prostheses. Quantitative comparison of the effects of four types of medullary treatment on bone ingrowth in a canine model [see comments]. J Bone Joint Surg Am 1993, 75:845-862.

26. Piermattei DL, Greeley RG: An Atlas of Approaches to the Bones of the Dog and Cat Philadelphia: W.B. Saunders Company; 1962.

27. Olmstead ML: The canine cemented modular total hip prosthesis. J Am Anim Hosp Assoc 1995, 31: 109-124.

28. Olmstead ML: Canine cemented total hip replacements: state of the art. J Small Anim Pract 1995, 36:395-399.

29. Green LC, Wagner DA, Glogowski J, Skipper PL, Wishnok JS, Tannenbaum SR: Analysis of nitrate, nitrite, and [15N]nitrate in biological fluids. Anal Biochem 1982, I 26:131-138.

30. Stadler J, Stefanovic-Racic M, Billiar TR, Curran RD, Mclntyre LA, Georgescu HI, Simmons RL, Evans CH: Articular chondrocytes synthesize nitric oxide in response to cytokines and lipopolysaccharide. J Immunol 1991, 147:3915-3920.

31. Akens MK, von Rechenberg B, Bittmann P, Nadler D, Zlinszky K, Auer JA: In-vitro Studies of photooxidized bovine articular cartilage. Journal of Veterinary Medicine, Series A 2002.

32. Georgescu HI, Mendelow D, Evans CH: HIG-82: an established cell line from rabbit periarticular soft tissue, which retains the "activatable" phenotype. In Vitro Cell Dev Biol 1988, 24:1015-1022. 
33. Nemeth GG, Heydemann A, Bolander ME: Isolation and analysis of ribonucleic acids from skeletal tissues. Anal Biochem 1989, 183:301-304.

34. Heinzerling LM, Feige K, Rieder S, Akens MK, Dummer R, Stranziger $G$, Moelling K: Tumor regression induced by intramural injection of DNA coding for human interleukin 12 into melanoma metastases in gray horses. Journal of Molecular Medicine 200I, 78:692-702.

35. Katz RP, Callaghan JJ, Sullivan PM, Johnston RC: Results of cemented femoral revision total hip arthroplasty using improved cementing techniques. Clin Orthop 1995: I78-183.

36. Noble PC, Collier MB, Maltry JA, Kamaric E, Tullos HS: Pressurization and centralization enhance the quality and reproducibility of cement mantles. Clin Orthop 1998:77-89.

37. Schulz KS, Stover SM, Kass PH, Vasseur PB, Koehler C: Effect of surgical technique and use of a rigid centralizing device on stem positioning and geometric reconstruction in the sagittal plane during total hip replacement in canine cadavers [In Process Citation]. Am J Vet Res 1999, 60: I I26-I I 35.

38. Yee A, Binnington A, Hearn T, Protzner K, Fomasier V, Davey J: Use of polyglilide lactide cement plug restrictor in total hip arthroplasty. Clin Orthop 1999, 364:254-266.

39. Klapach AS, Callaghan J], Goetz DD, Olejniczak JP, Johnston RC: Charnley total hip arthroplasty with use of improved cementing techniques: a minimum twenty-year follow-up study. J Bone Joint Surg 200I, 83-A: 1840-I848.

40. Shahar R, Banks-Sills L, Eliasy R: Mechanics of the canine femur with two types of hip replacement stems. Vet Comp Orthop Taumatol 2003, 3: | $45-152$.

4I. Hukkanen M, Corbett SA, Platts LAM, Konttinen YT, Hughes SPF, Polak JM: Nitric oxide in the local host reaction to total hip replacement. Clinical Orhopaedics and Related Research 1998, 352:53-65

42. Hukkanen M, Corbett SA, Platts LAM, Konttinen YT, Hughes SPF, Polak JM: Nitric oxide in the local hoist reaction to total hip replacement. Clinical Orhopaedics and Related Research 1998, 352:53-65.

43. von Rechenberg B, Mcllwraith CW, Akens M, Leutenegger C, Auer JA: Spontaneous production of nitric oxide (NO), prostaglandin (PGE2) and neutral metalloproteinases (NMPs) in media of explant cultures of equine synovial membrane and articular cartilage from normal and osteoarthritic joints. Equine Vet I 2000, 32: 140-150.

44. Abbuehl U: Biochemical and histological changes at the cement interface associated with aseptic loosening of the implant, using canine hip prosthesis as a model: a preliminary study Zurich: Zurich; 1999

45. Horowitz SM, Rapuano BP, Lane JM, Burstein AH: The interaction of the macrophage and the osteoblast in the pathophysiology of aseptic loosening of joint replacements. Calcif Tissue Int 1994, 54:320-324.

46. Karrholm J, Borssen B, Lowenhielm G, Snorrason F: Does early micromotion of femoral stem prostheses matter? 4-7-year stereoradiographic follow-up of 84 cemented prostheses. J Bone Joint Surg Br 1994, 76:912-917.

47. Birkedal-Hansen H: Role of Cytokines and Inflammatory Mediators in Tissue Destruction. Journal of Periodontal Research 1993, 28:500-510

48. Birkedal-Hansen $\mathrm{H}$ : Role of Matrix Metalloproteinases in Human Periodontal Diseases. Journal of Periodontology 1993, 64:474-484.

49. Waselau M: Aseptic loosening of titanium-aluminum-vanadium implants: a possible explanation at the level of clinical, histological and biochemical evaluations Zurich: University of Zurich; Doctorate thesis.; 2002.

\section{Pre-publication history}

The pre-publication history for this paper can be accessed here:

http://www.biomedcentral.com/1471-2474/5/7/prepub
Publish with Biomed Central and every scientist can read your work free of charge

"BioMed Central will be the most significant development for disseminating the results of biomedical research in our lifetime. "

Sir Paul Nurse, Cancer Research UK

Your research papers will be:

- available free of charge to the entire biomedical community

- peer reviewed and published immediately upon acceptance

- cited in PubMed and archived on PubMed Central

- yours - you keep the copyright

Submit your manuscript here:

http://www.biomedcentral.com/info/publishing_adv.asp
BiolMedcentral 